\title{
Report on the Synchrotron
} Characterization of U-Mo and $U$-Zr Alloys and the Modeling Results

\section{Fuel Cycle Research \& Development Advanced Fuels Campaign}

Maria A. Okuniewski ${ }^{1}$, Daniel Velazquez ${ }^{2}$, Rachel Seibert ${ }^{2}$, Jeff Terry ${ }^{2}$, Varsha Ganapathy ${ }^{1}$, Brenden Hamilton ${ }^{1}$,

David Sprouster ${ }^{3}$, Lynne Ecker ${ }^{3}$, Mohamed Elbakhshwan ${ }^{3}$, Paul Cassutt ${ }^{1}$, Fan Zhang ${ }^{1}$

1 Purdue University, 701 West Stadium Ave., West Lafayette, IN 47907, USA

2 Illinois Institute of Technology, 3300 S Federal St, Chicago, IL 60616, USA

3 Brookhaven National Laboratory, 20 Brookhaven Ave, Upton, NY 119

Prepared for

U.S. Department of Energy Office of Nuclear Energy

September 2016

FCRD-FUEL-2016-000244 


\section{DISCLAIMER}

This information was prepared as an account of work sponsored by an agency of the U.S. Government. Neither the U.S. Government nor any agency thereof, nor any of their employees, makes any warranty, expressed or implied, or assumes any legal liability or responsibility for the accuracy, completeness, or usefulness, of any information, apparatus, product, or process disclosed, or represents that its use would not infringe privately owned rights. References herein to any specific commercial product, process, or service by trade name, trade mark, manufacturer, or otherwise, does not necessarily constitute or imply its endorsement, recommendation, or favoring by the U.S. Government or any agency thereof. The views and opinions of authors expressed herein do not necessarily state or reflect those of the U.S.

fonsarnmant ar anis soanri tharanf 
INL/EXT-16-40130

Revision 0

\title{
Report on the Synchrotron Characterization of U-Mo and U-Zr Alloys and the Modeling Results
}

\author{
Maria A. Okuniewski ${ }^{1}$, Daniel Velazquez ${ }^{2}$, Rachel Seibert ${ }^{2}$, Jeff Terry ${ }^{2}$, Varsha \\ Ganapathy ${ }^{1}$, Brenden Hamilton ${ }^{1}$, David Sprouster ${ }^{3}$, Lynne Ecker ${ }^{3}$, Mohamed \\ Elbakhshwan $^{3}$, Paul Cassutt ${ }^{1}$, Fan Zhang ${ }^{1}$ \\ 1 Purdue University, 701 West Stadium Ave., West Lafayette, IN 47907, USA \\ 2 Illinois Institute of Technology, 3300 S Federal St, Chicago, IL 60616, USA \\ 3 Brookhaven National Laboratory, 20 Brookhaven Ave, Upton, NY 11967, USA
}

September 2016

\begin{abstract}
Idaho National Laboratory
Idaho Falls, Idaho 83415
\end{abstract}

http://www.inl.gov

\author{
Prepared for the \\ U.S. Department of Energy \\ Office of Nuclear Energy \\ Under DOE Idaho Operations Office \\ Contract DE-AC07-05ID14517
}


INTENTIONALLY BLANK 


\begin{abstract}
Uranium-molybdenum (U-Mo) and uranium-zirconium (U-Zr) are two promising fuel candidates for nuclear transmutation reactors which burn long-lived minor actinides and fission products within fast spectrum reactors. The objectives of this research are centered on understanding the early stages of fuel performance through the examination of the irradiation induced microstructural changes in $\mathrm{U}-\mathrm{Zr}$ and $\mathrm{U}$ Mo alloys subjected to low neutron fluences. Specimens that were analyzed include those that were previously irradiated in the Advanced Test Reactor at INL. This most recent work has focused on a subset of the irradiated specimens, specifically U-Zr and U-Mo alloys that were irradiated to $0.01 \mathrm{dpa}$ at temperatures ranging from $\left(150-800^{\circ} \mathrm{C}\right)$. These specimens were analyzed with two types of synchrotron techniques, including X-ray absorption fine structure and X-ray diffraction. These techniques provide non-destructive microstructural analysis, including phase identification and quantitation, lattice parameters, crystallite sizes, as well as bonding, structure, and chemistry. Preliminary research has shown changes in the phase fractions, crystallite sizes, and lattice parameters as a function of irradiation and temperature. Future data analyses will continue to explore these microstructural changes.
\end{abstract}


INTENTIONALLY BLANK 


\section{CONTENTS}

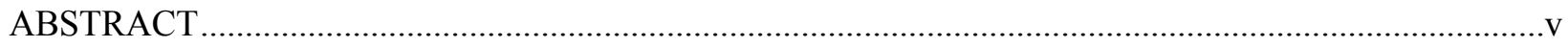

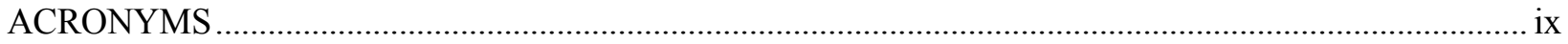

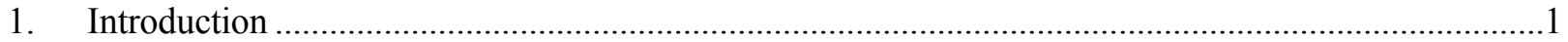

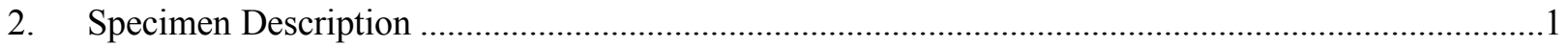

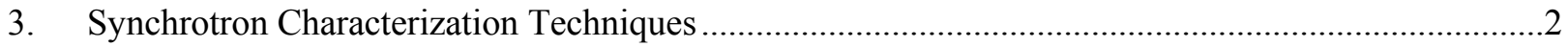

3.1 X-ray Absorption Fine Structure (XAFS) ...................................................................... 2

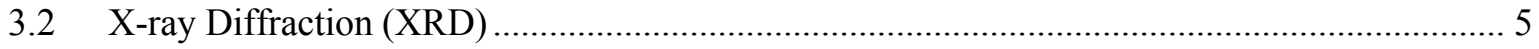

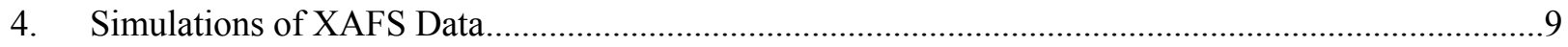

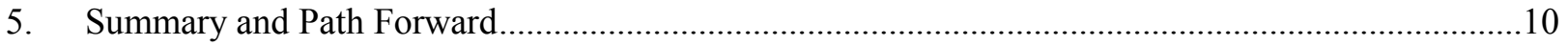

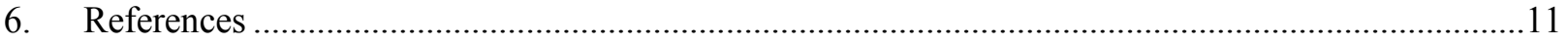




\section{FIGURES}

Figure 3-1. Beamline 10-ID illustrating (1) harmonic rejection mirror, (2) slits, (3) input ion chamber, (4) sample stage, (5) output ion chamber, (6) microfocusing table, and (7)

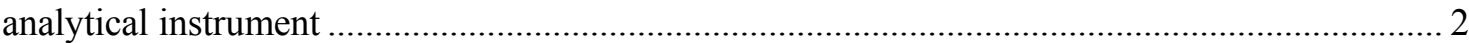

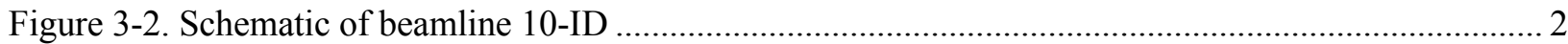

Figure 3-3. XAFS spectrum of pure Zr measured at the $\mathrm{Zr}$ edge region. Blue line indicates control sample and the red and green lines indicate 0.01 dpa specimens irradiated at various temperatures. Inset indicates the XANES region. 3

Figure 3-4. XAFS spectrum of pure $U$ measured at the $U$ edge region. Blue line indicates control sample and the other colors indicate $0.01 \mathrm{dpa}$ specimens irradiated at various temperatures. Inset indicates the XANES region. 3

Figure 3-5. XAFS spectrum of U10Zr measured at the $\mathrm{Zr}$ edge region. Blue line indicates control sample and the other colors indicate $0.01 \mathrm{dpa}$ specimens irradiated at various temperatures. Inset indicates the XANES region.

Figure 3-6. XAFS spectrum of U10Zr measured at the U edge region. Blue line indicates control sample and the other colors indicate $0.01 \mathrm{dpa}$ specimens irradiated at various temperatures. Inset indicates the XANES region. 4

Figure 3-7. XAFS data analysis flow chart for Athena and Artemis. ......................................................... 5

Figure 3-8. NSLS II XPD beamline. Note the robotic sample changer (red) ............................................. 6

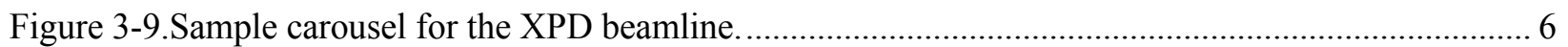

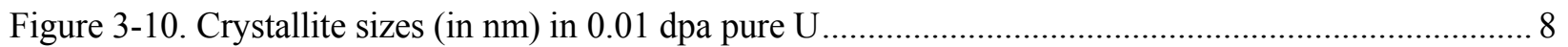

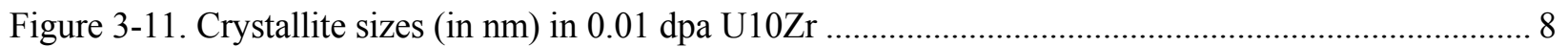

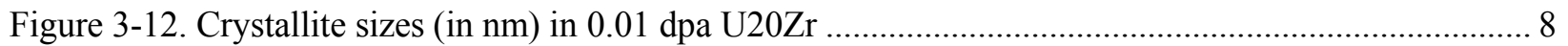

Figure 4-1. MD simulations of melting point determination in $\mathrm{Zr}$ (left) and bec $\mathrm{U}$ (right)........................ 9

Figure 4-2. Input file from MD simulations to ARTEMIS/ATHENA …....................................................... 10

TABLES

Table 2-1. Specimen description and irradiation conditions. ................................................................. 1

Table 3-1. Pure U lattice parameters and phase fractions. .......................................................................... 7

Table 3-2. U10wt $\%$ Zr lattice parameters and phase fractions. ................................................................. 7

Table 3-3.U20wt\%Zr lattice parameters and phase fractions. ................................................................. 7 


\section{ACRONYMS}

$\begin{array}{ll}\text { APS } & \text { Advanced Photon Source } \\ \text { bcc } & \text { body-centered cubic } \\ \text { BNL } & \text { Brookhaven National Laboratory } \\ \text { DOE } & \text { Department of Energy } \\ \text { EXAFS } & \text { extended X-ray absorption fine structure } \\ \text { INL } & \text { Idaho National Laboratory } \\ \text { MD } & \text { molecular dynamics } \\ \text { Mo } & \text { molybdenum } \\ \text { NSLS II } & \text { National Synchrotron Light Source II } \\ \text { TEM } & \text { transmission electron microscope } \\ \text { U } & \text { uranium } \\ \text { XAFS } & \text { X-ray absorption fine structure } \\ \text { XANES } & \text { X-ray absorption near edge spectroscopy } \\ \text { XRD } & \text { X-ray diffraction } \\ \text { Zr } & \text { zirconium }\end{array}$


INTENTIONALLY BLANK 


\section{Report on the Synchrotron Characterization of U-Mo and U-Zr Alloys and the Modeling Results}

\section{Introduction}

Uranium-molybdenum (U-Mo) and uranium-zirconium (U-Zr) are two promising fuel candidates for nuclear transmutation reactors which burn long-lived minor actinides and fission products within fast spectrum reactors. The previous research that has been conducted over the past few decades has primarily focused on performance-based criteria to test the efficacy of the fuels at high burn-ups. Consequently, there has been a lack of understanding of the fuel behavior during low burn-up (or low fluence), which can have a significant influence on later stages of irradiation. The objectives of this research are centered on understanding the early stages of fuel performance through the examination of the irradiation induced microstructural changes in U-Zr and U-Mo alloys subjected to low neutron fluences. These experiments can be utilized to help parameterize and validate various fuel performance models, including those currently conducted under the Nuclear Energy Advanced Modeling and Simulation (NEAMS) program. This proposed research will use the state-of-the-art synchrotron-based characterization techniques (via the Advanced Test Reactor National Scientific User Facility-ATR NSUF), existing experimental capabilities, and complementary multiscale modeling to assess radiation damage effects on the microstructure, as well as mechanical properties resulting from recent low fluence neutron irradiations (up to $1 \mathrm{dpa}$ with temperatures ranging from 150 to $800^{\circ} \mathrm{C}$ ) which have been previously completed on metallic fuel alloys, including a number of U-Zr and U-Mo systems as part of an ATR NSUF irradiation experiment.

\section{Specimen Description}

Specimens that were analyzed are those that were previously irradiated in the Advanced Test Reactor at INL as part of an ATR NSUF awarded irradiation project. This most recent work has focused on a subset of the irradiated specimens, specifically U-Zr and U-Mo alloys that were irradiated to $0.01 \mathrm{dpa}$ at temperatures ranging from $\left(150-800^{\circ} \mathrm{C}\right)$. At this point, only the lowest dose was analyzed due to the high radiological dose rate readings of the specimens and the ability of other facilities to accept them.

The overall specimen matrix that will be investigated in this proposed project is given in Table 1 below. Note that the compositions reflect a weight percentage. The shaded regions in the table indicate the specimens available for this study. The irradiation temperatures were selected such that they represented typical operating conditions in both transmutation and research reactors. The alloy compositions were also determined to represent typical reactor fuel compositions.

Table 2-1. Specimen description and irradiation conditions.

\begin{tabular}{|c|c|c|c|c|c|c|c|c|}
\hline $\begin{array}{c}\text { Fluences } \\
\text { (dpa) }\end{array}$ & $\begin{array}{l}\text { Design } \\
\text { Temp } \\
\left({ }^{\circ} \mathrm{C}\right)\end{array}$ & $\mathbf{U}$ & $\begin{array}{c}\mathrm{U}- \\
10 \mathrm{Zr}\end{array}$ & $\begin{array}{c}\mathrm{U}- \\
15 \mathrm{Zr}\end{array}$ & $\begin{array}{c}\text { U- } \\
20 \mathrm{Zr}\end{array}$ & U-7Mo & $\begin{array}{c}\text { U- } \\
\text { 10Mo } \\
\text { (foil) }\end{array}$ & $\begin{array}{c}\text { U- } \\
10 \mathrm{Mo} \\
\text { (cast) }\end{array}$ \\
\hline \multirow{7}{*}{$\begin{array}{l}0.01, \\
0.1 \\
1.0\end{array}$} & 150 & & & & & & & \\
\hline & 250 & & & & & & & \\
\hline & 350 & & & & & & & \\
\hline & 500 & & & & & & & \\
\hline & 600 & & & & & & & \\
\hline & 700 & & & & & & & \\
\hline & 800 & & & & & & & \\
\hline
\end{tabular}




\section{Synchrotron Characterization Techniques}

Three synchrotron techniques were utilized to evaluate the U-Zr and U-Mo alloys. These techniques included X-ray absorption fine structure (XAFS) and X-ray diffraction (XRD). The XAFS measurements were performed at MR-CAT at the Advanced Photon Source (APS) at Argonne National Laboratory (as part of the ATR NSUF), whereas the XRD measurements were performed at the National Synchrotron Light Source II (NSLS II) at Brookhaven National Laboratory.

\subsection{X-ray Absorption Fine Structure (XAFS)}

Synchrotron XAFS measurements are useful in examining bond length, coordination number, and disorder. This information will provide additional insight regarding the phase decomposition mechanisms and irradiation effects on chemical bonding. The data obtained within XAFS measurements can be divided into two regimes: (1) X-ray absorption near edge spectroscopy (XANES) and (2) extended X-ray absorption fine-edge structure spectroscopy (EXAFS). As previously mentioned, these experiments were carried out at MR-CAT at the APS. Figure 3-1 shows a picture of the beamline layout and Figure 3-2 shows a schematic of the beamline. The TEM disk specimens were measured in multiple locations within the disk, as well as repeated measurements were taken in the same region. Typical count time was $0.5 \mathrm{~s}$. The beam characteristics were as follows: $\mathrm{U}$ edge $-17.0-18.0 \mathrm{keV}, \mathrm{Zr}$ edge $-17.8-18.8 \mathrm{keV}$, and Mo edge $-19.8-21.2 \mathrm{keV}$.

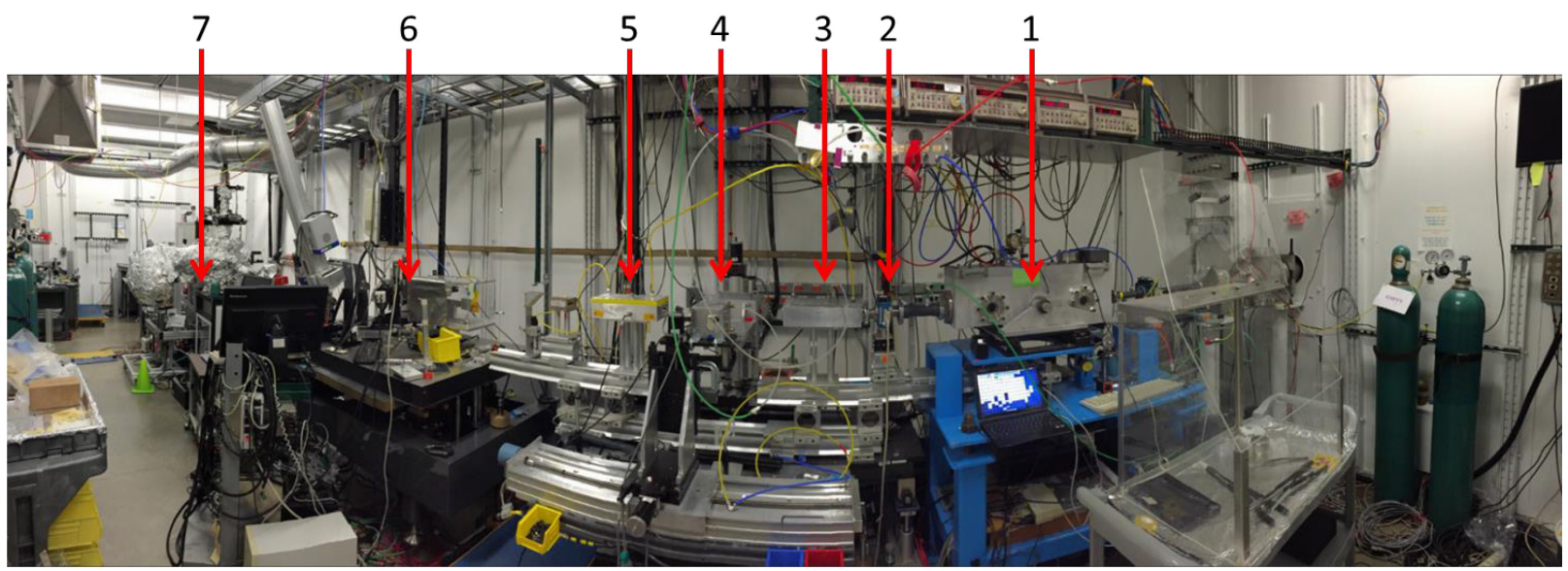

Figure 3-1. Beamline 10-ID illustrating (1) harmonic rejection mirror, (2) slits, (3) input ion chamber, (4) sample stage, (5) output ion chamber, (6) microfocusing table, and (7) analytical instrument.

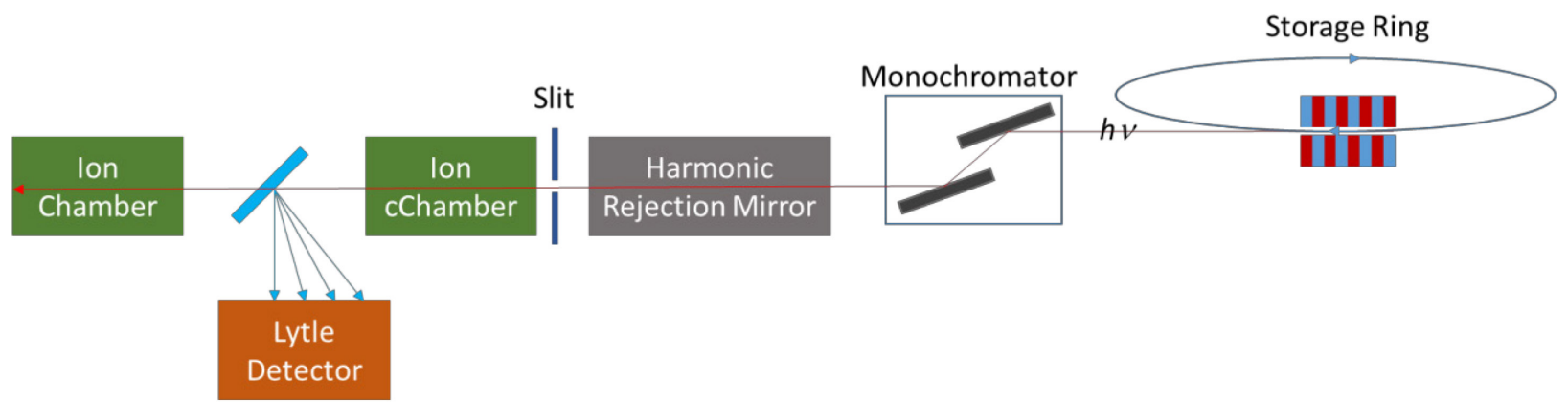

Figure 3-2. Schematic of beamline 10-ID. 
Examples of the preliminary data for the XAFS results, including both the EXAFS and XANES regions are shown in Figure 3-3 to Figure 3-6. This data has accounted for background subtraction and normalization. The inset region indicates the XANES data, which provides information regarding coordination, chemistry, and disorder. The changes in the peaks and valleys correspond to actual changes in atomic information. Future analysis will include the fitting of this data with measured standards as well as unirradiated specimens.

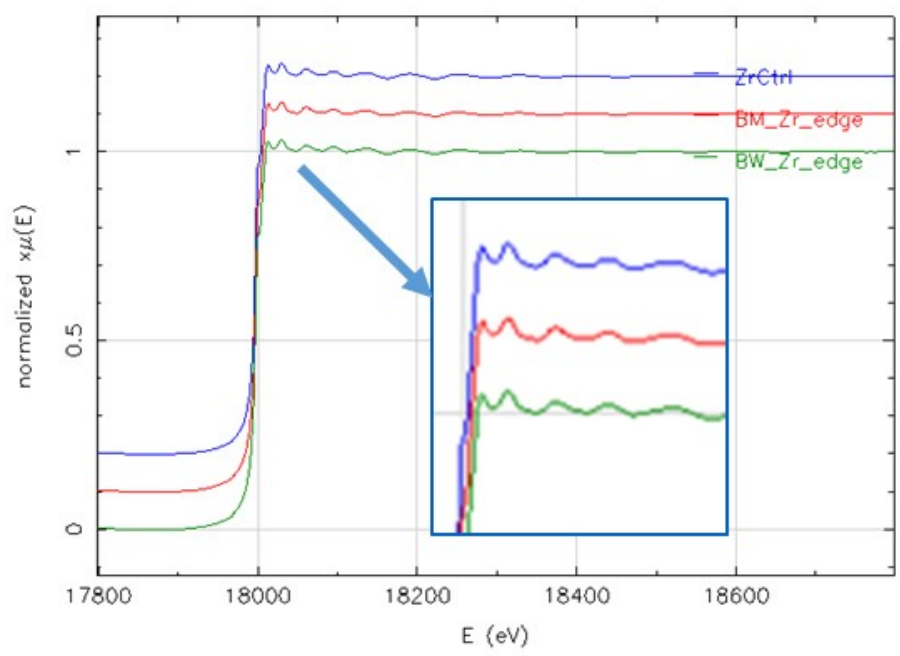

Figure 3-3. XAFS spectrum of pure $\mathrm{Zr}$ measured at the $\mathrm{Zr}$ edge region. Blue line indicates control sample and the red and green lines indicate $0.01 \mathrm{dpa}$ specimens irradiated at various temperatures. Inset indicates the XANES region.

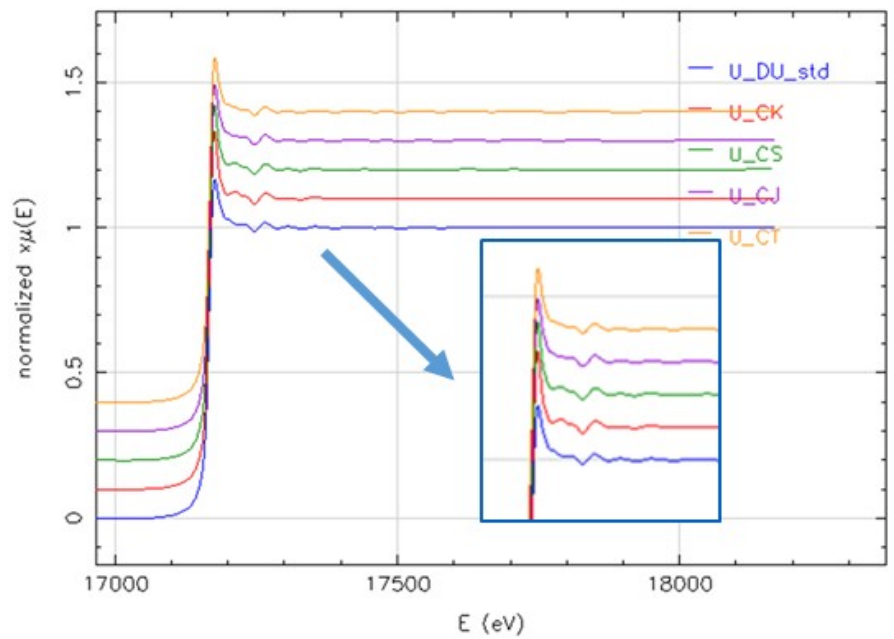

Figure 3-4. XAFS spectrum of pure $U$ measured at the $U$ edge region. Blue line indicates control sample and the other colors indicate $0.01 \mathrm{dpa}$ specimens irradiated at various temperatures. Inset indicates the XANES region. 


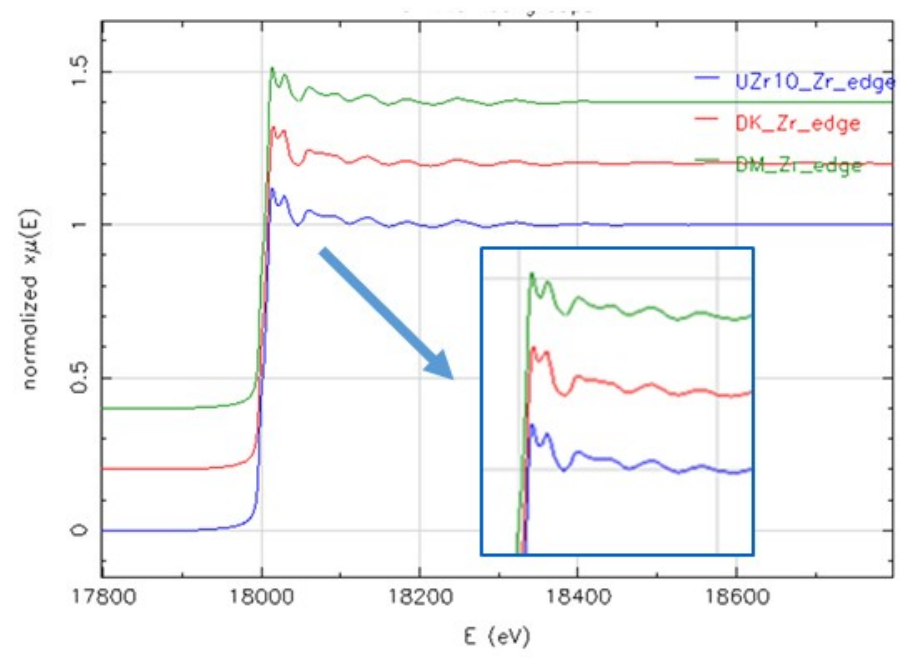

Figure 3-5. XAFS spectrum of U10Zr measured at the Zr edge region. Blue line indicates control sample and the other colors indicate $0.01 \mathrm{dpa}$ specimens irradiated at various temperatures. Inset indicates the XANES region.

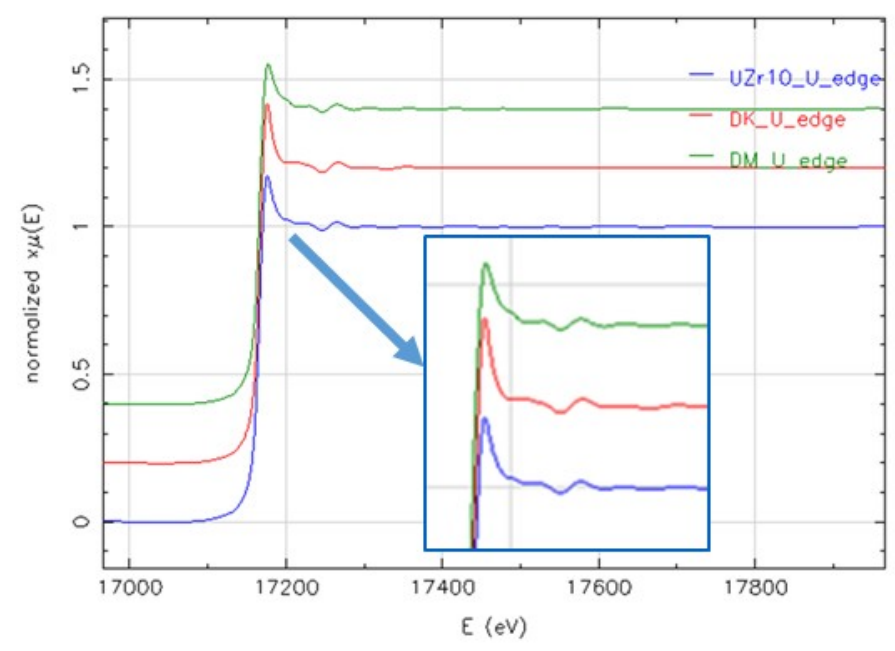

Figure 3-6. XAFS spectrum of U10Zr measured at the U edge region. Blue line indicates control sample and the other colors indicate $0.01 \mathrm{dpa}$ specimens irradiated at various temperatures. Inset indicates the XANES region.

The Athena/Artemis Software package has been utilized to conduct the initial processing and background subtraction of the absorption spectra. A schematic of how the data is processed within this software is shown below in Figure 3-7. In this upcoming year, we will work to combine the fitting of the theoretical models and the data. 


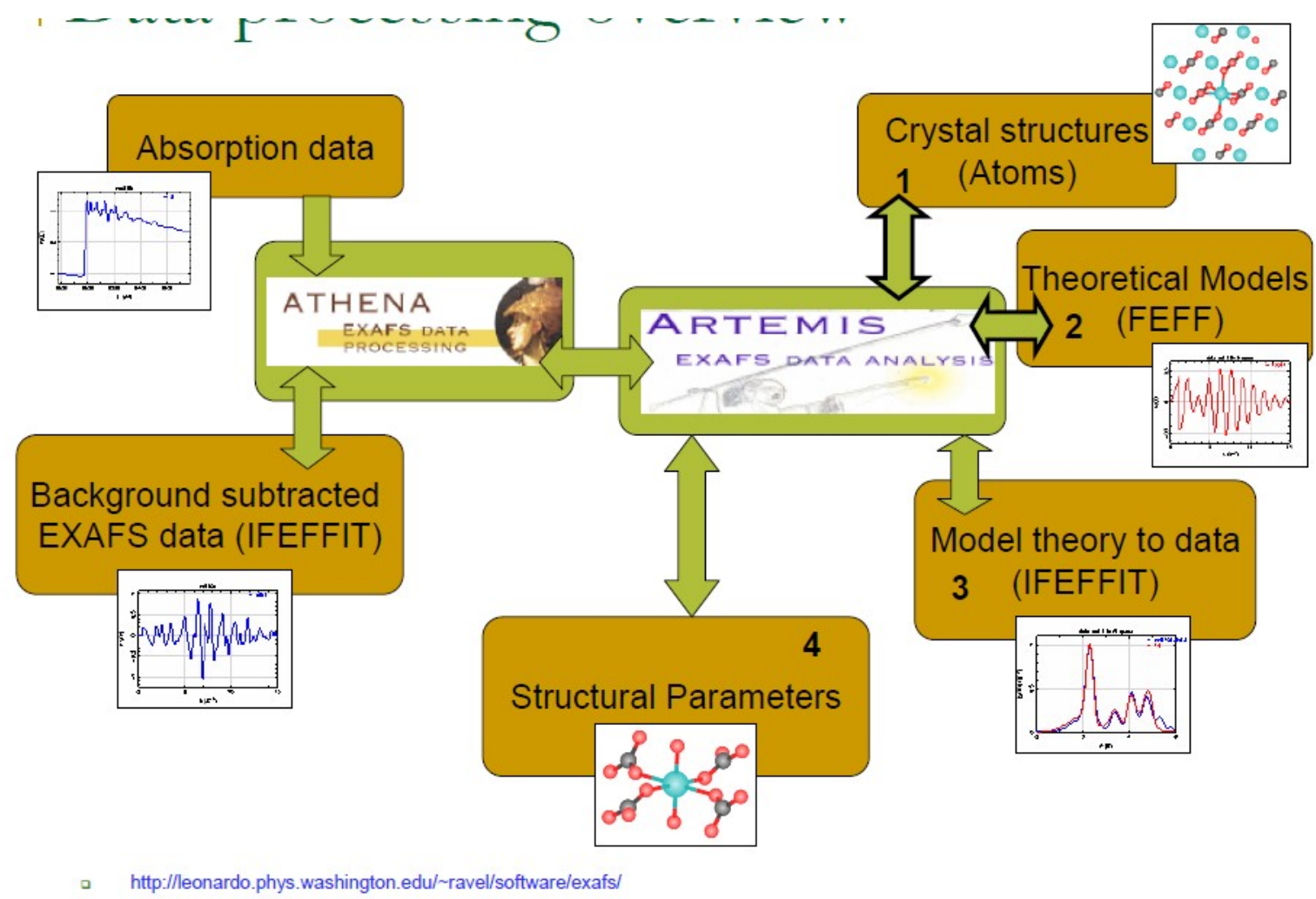

Figure 3-7. XAFS data analysis flow chart for Athena and Artemis.

\subsection{X-ray Diffraction (XRD)}

Synchrotron XRD experiments can effectively determine the bulk phase composition and phase fractions, as well as when these transitions occur as a function of irradiation dose and temperature. The XRD measurements were conducted at NSLS II on beamline XPD, Figure 3-8. The sample carousel is shown in Figure 3-9. The energy used was $52.5 \mathrm{keV}$ with slit sizes that were approximately $0.5 \mathrm{~mm} \times 0.5$ $\mathrm{mm}$. The exposure time ranged from 0.5 to $1.0 \mathrm{sec}$ depending upon the specimens. Two types of measurements were taken: stationary and spinning. The spinning measurements were intended to reduce issues with texture and to create a more "powder-like" diffraction pattern.

The changes in lattice parameters and phase fractions for pure U, U10Zr, and U20Zr are shown in Table 3-1 to Table 3-3, respectively. The lattice parameter changes with differences in chemistry and irradiation, which could indicate a reflection of point and extended defects. The pure irradiated U specimens showed the existence of UO2 and potentially UC or UN in small concentrations as well. The irradiated UZr alloys showed both phases that were expected in these systems, including the $\delta-\mathrm{UZr}_{2}$ and the $\gamma$-UZr phases. Figure 3-10 to Figure 3-12 show the changes is crystallite size as a function of material and irradiation temperature. It can be seen that there is recrystallization of $\alpha-U$ in the pure $U$ system. Also the crystallite size decreases in the UZr materials with increasing temperatures, potentially due to the extended defect formations. 


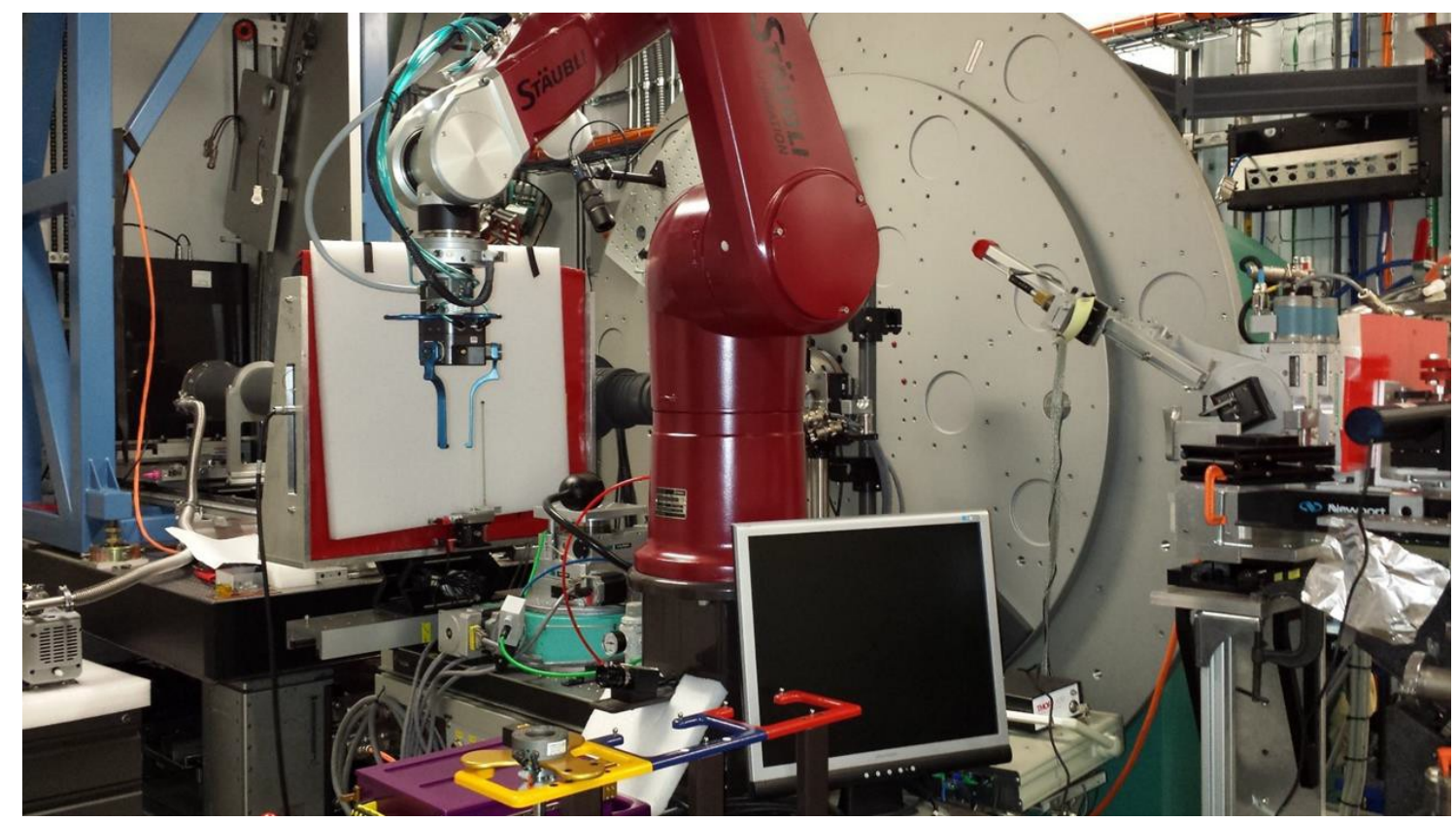

Figure 3-8. NSLS II XPD beamline. Note the robotic sample changer (red).

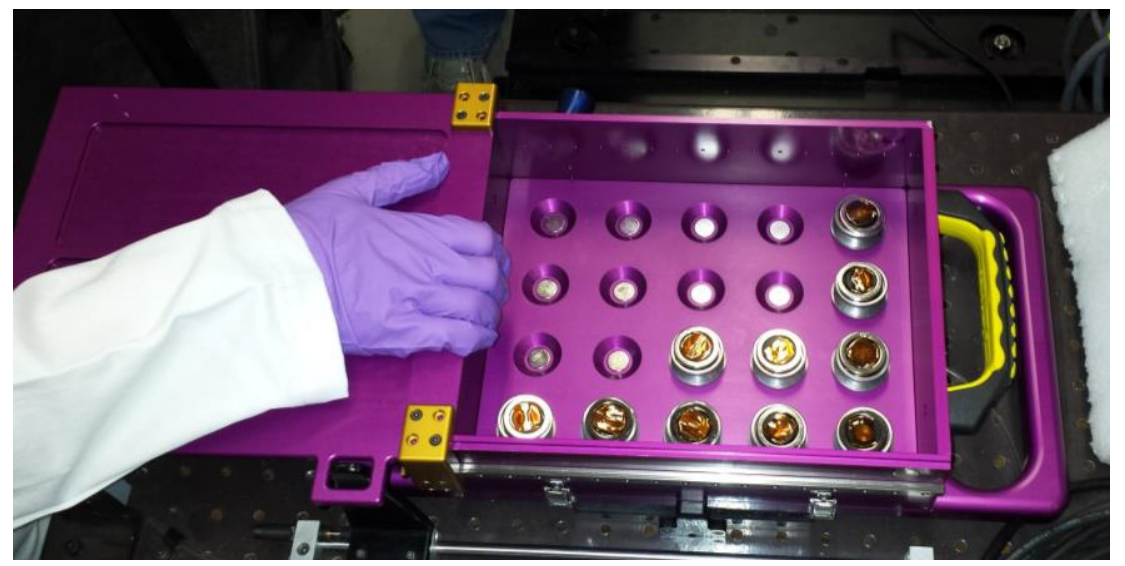

Figure 3-9.Sample carousel for the XPD beamline. 
Table 3-1. Pure U lattice parameters and phase fractions.

\begin{tabular}{|l|l|l|l|r|}
\hline & $a(\AA)$ & $b(\AA)$ & $c(\AA)$ & Fraction \\
\hline \multicolumn{1}{|c|}{ U - 150oC } & & & & \\
\hline$\alpha-U$ & 2.8526 & 5.8604 & 4.9536 & 98.6 \\
\hline UO2 & 5.4616 & & & 1.1 \\
\hline UN / UC & 4.9169 & & & 0.3 \\
\hline \multicolumn{1}{|c|}{ U - 800oC } & & & & \\
\hline$\alpha-U$ & 2.8524 & 5.8625 & 4.9528 & 98.5 \\
\hline UO2 & 5.4579 & & & 1 \\
\hline UN / UC? & 4.9149 & & & 0.6 \\
\hline
\end{tabular}

Table 3-2. U10wt $\% \mathrm{Zr}$ lattice parameters and phase fractions.

\begin{tabular}{|l|r|r|r|r|}
\hline & a $(\AA)$ & $b(\AA)$ & $c(\AA)$ & Fraction \\
\hline U10wt\%Zr - 500oC & & & & \\
\hline$\alpha-U$ & 2.863 & 5.837 & 4.978 & 93.2 \\
\hline UZr2 & 5.023 & & 3.092 & 6.75 \\
\hline U10wt\%Zr - 800oC & & & & \\
\hline$\alpha-U$ & 2.867 & 5.83 & 4.982 & 96.1 \\
\hline UZr2 & 5.008 & & 3.079 & 3.9 \\
\hline
\end{tabular}

Table 3-3.U20wt $\% \mathrm{Zr}$ lattice parameters and phase fractions.

\begin{tabular}{|l|r|r|r|r|}
\hline & a $(\AA)$ & $b(\AA)$ & $c(\AA)$ & Fraction \\
\hline U20wt\%Zr - 600oC & & & & \\
\hline$\alpha-U$ & 2.87 & 5.832 & 4.985 & 88.2 \\
\hline$U Z r 2$ & 5.022 & & 3.069 & 11.8 \\
\hline U20wt\%Zr - 800oC & & & & \\
\hline$\alpha-U$ & 2.869 & 5.828 & 4.992 & 88.3 \\
\hline UZr2 & 5.014 & & 3.079 & 11.7 \\
\hline
\end{tabular}




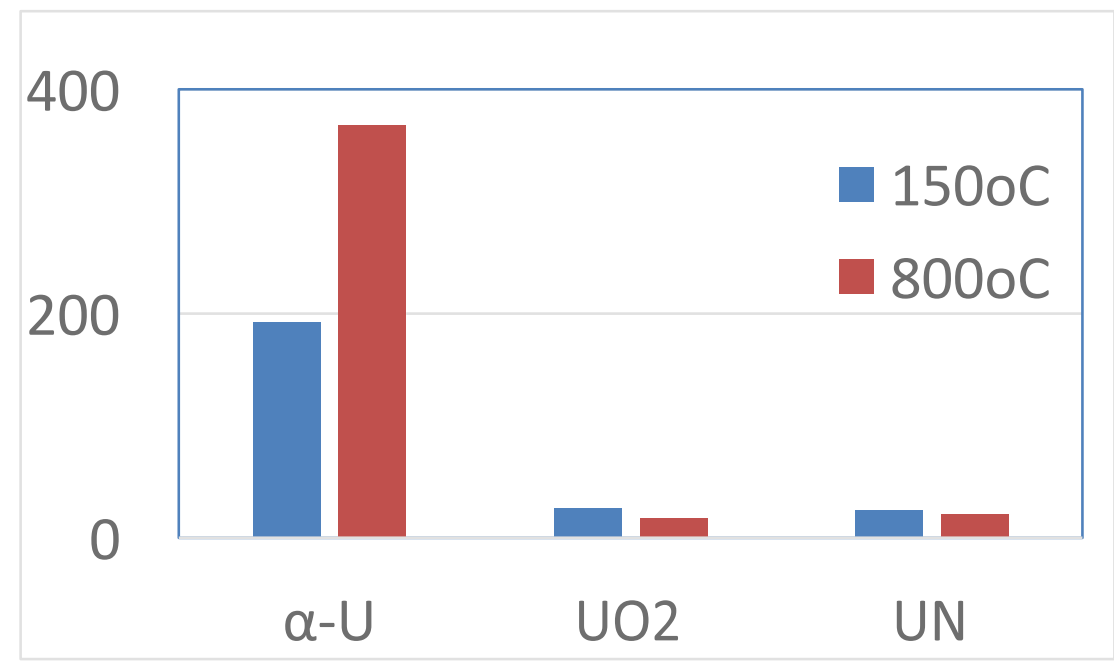

Figure 3-10. Crystallite sizes (in $\mathrm{nm}$ ) in $0.01 \mathrm{dpa}$ pure U.

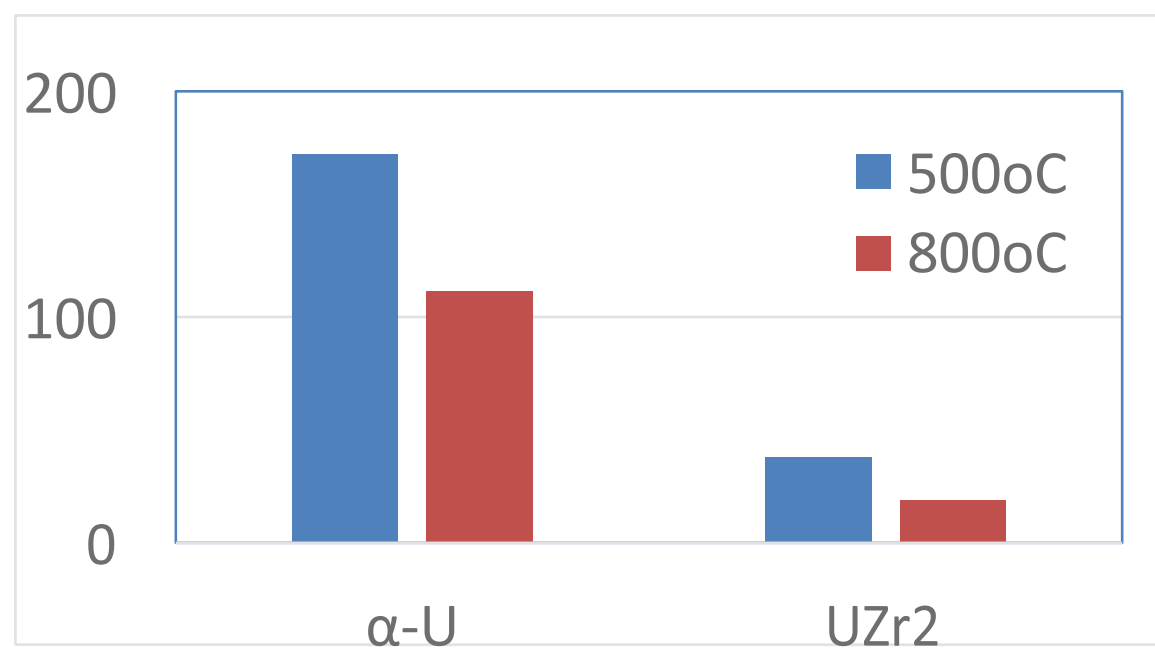

Figure 3-11. Crystallite sizes (in nm) in $0.01 \mathrm{dpa}$ U10Zr.

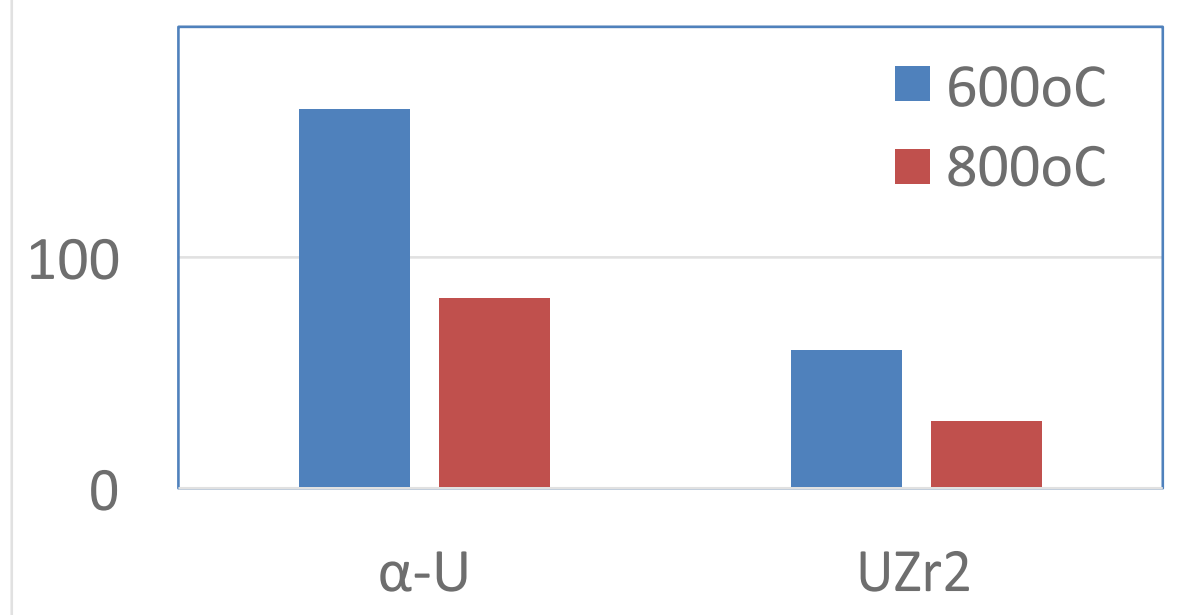

Figure 3-12. Crystallite sizes (in nm) in $0.01 \mathrm{dpa}$ U20Zr. 


\section{Simulations of XAFS Data}

The details of the XAFS data analysis flowchart using the Athena and Artemis software is shown above in Figure 3-7. As part of this analysis, it is necessary to construct theoretical atomistic structures to be able to compare to and interpret the spectroscopy data. Ultimately, this will lead to the appropriate determination of the structural parameters of the low fluence irradiated metallic fuels.

In order to accomplish this, we have conducted molecular dynamics (MD) simulations with both pure $\mathrm{Zr}$ and pure $\mathrm{U}$. The Mendelev interatomic potential was used for the $\mathrm{Zr}$ simulations [1]. The Smirnova interatomic potential was utilized for the pure U simulations [2]. Figure 4-1 shows examples of these simulations. On the left hand side, $\mathrm{Zr}$ is modeled to verify the reported melting temperature of the Mendelev potential. On the right, a pure U system that body-centered cubic (bcc) is shown. After the appropriate modeling conditions and end stages have been reached in the MD simulations, it is necessary to create a compatible input file for ARTEMIS/ATHENA. A successful snapshot of an input file is shown in Figure 4-2.

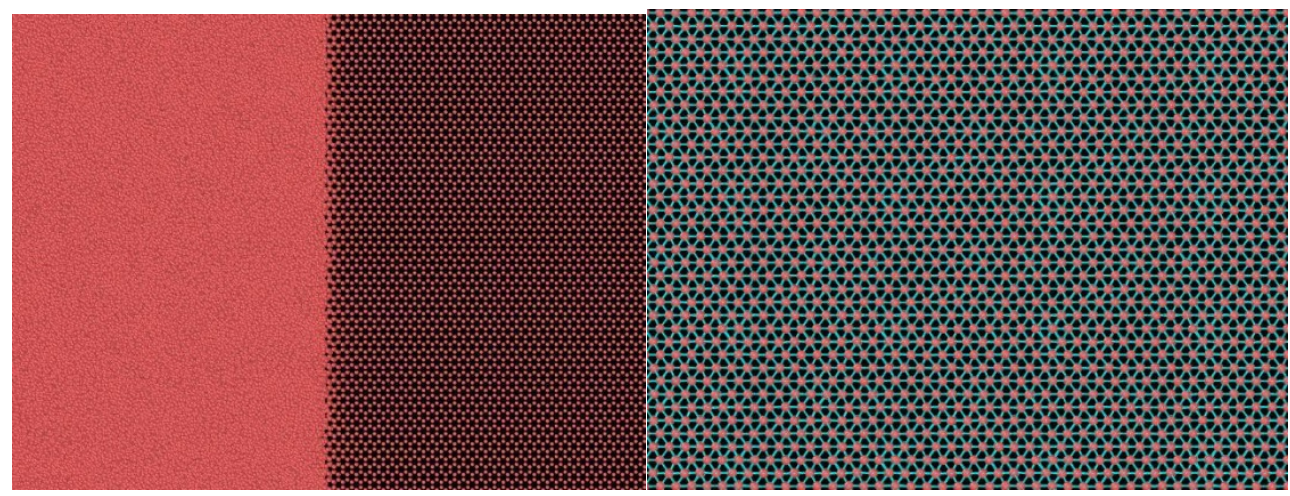

Figure 4-1. MD simulations of melting point determination in $\mathrm{Zr}$ (left) and bcc U (right). 


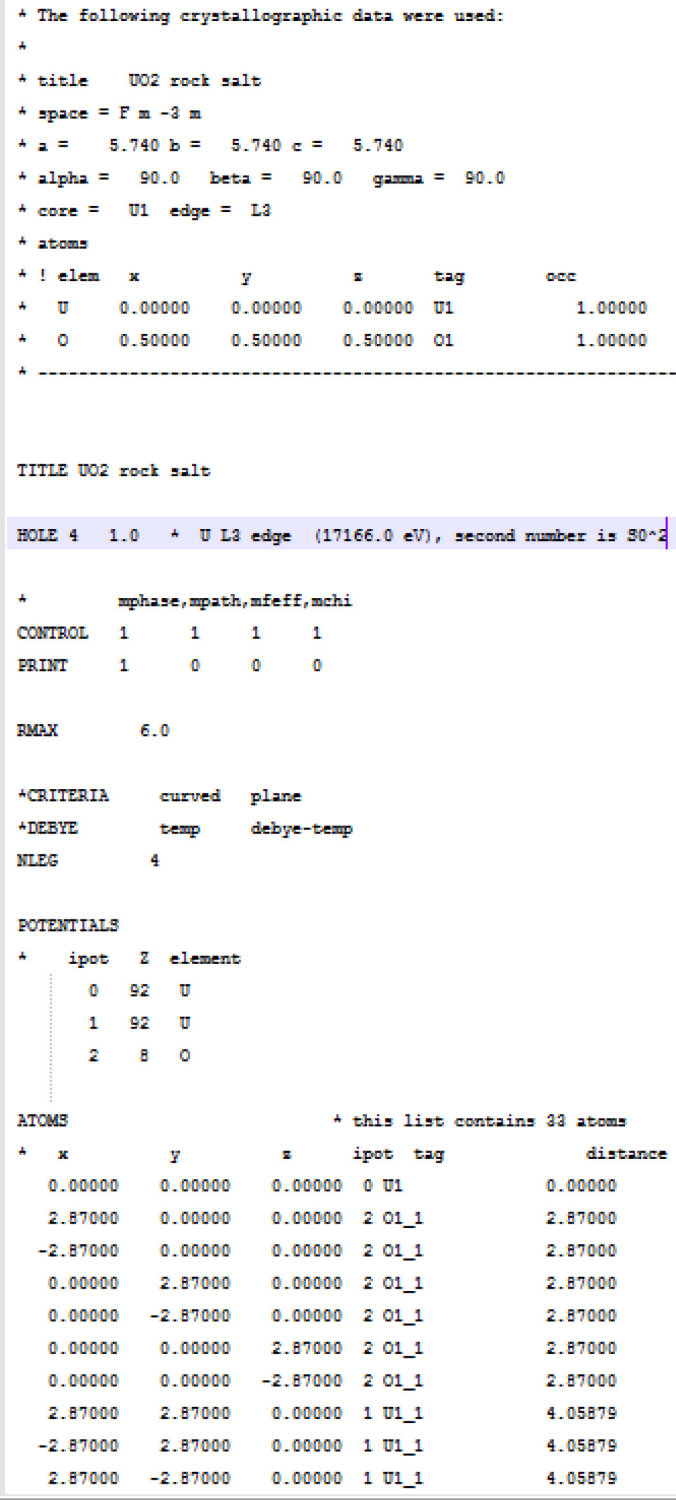

Figure 4-2. Input file from MD simulations to ARTEMIS/ATHENA

\section{Summary and Path Forward}

The initial synchrotron XRD data indicated changes in the material phase compositions, crystallite sizes, and lattice parameters for the low fluence irradiated U and UZr specimens. XAFS data also showed changes within the materials original structure following these irradiations. For both the XAFS and XRD techniques, additional data analysis is required to elucidate the microstructural phenomena occurring even at these low fluences. Additionally, more simulations will be conducted to help interpret the XAFS data to provide structural information. Moreover, electron microscopy will be conducted to compare the microstructures. In the upcoming fiscal year, we will analyze some of the higher fluence specimens with synchrotron and microscopy techniques. Additionally, a variety of simulations will be undertaken to help interpret the experimental data, as well as to explore defect energetics and kinetics, as well as diffusion in these metallic alloys. 


\section{References}

1. M. I. Mendelev and G. J. Ackland, Development of an interatomic potential for the simulation of phase transformations in zirconium. Philosophical Magazine Letters 87 (2007) 349-359.

2. D E Smirnova, S V Starikov, and V V Stegailov, Interatomic potential for uranium in a wide range of pressures and temperatures, Journal of Physics: Condensed Matter 24 (2011) 149501. 